\title{
IMPACTS OF LANDSCAPE ARCHITECTURE ON OUTDOOR INSECURITY IN URBAN HOUSING COMPLEXES
}

\author{
LAKCHAN A. H. \& UDALAMATHTHA S.
}

1,2Faculty of Architecture, University of Moratuwa, Katubedda, Sri Lanka,

1'harindulakchanice@gmail.com, ${ }^{2}$ susirasen@gmail.com

\begin{abstract}
Housing is one of the most essential components of life, offering shelter, protection, and comfort, as well as a place to rest. When considering the Sri Lankan housing complexes Millennium city housing complex was highlighted mainly because of the crime incidents that happened inside the housing complex. This research is done to demonstrate and to investigate the application of landscape architecture for security on urban housing complexes based on Millennium city housing complex, using landscape character to reduce outdoor insecurity. Seven places in the millennium city housing complex premises were selected to apply the crime prevention through environmental design theory and to observe its effectiveness through structured interviews and by considering the police reports that were taken through Sri Lanka police Athurugiriya. Natural surveillance, Territorial reinforcement, Maintenance, Prospect, Refuge, and Escape factors are separately discussed in the analysis regarding the selected places. A sectional survey is done for further analysis. The outcome shows that the house settings and the landscape character affect the outdoor landscape safety of the residents. The study will be a source to better understand how landscape architecture can be applied for outdoor security in urban housing complexes.
\end{abstract}

Keywords: Landscape Architecture, Outdoor insecurity, Urban housing complexes.

\section{Introduction}

Human well-being is a broad concept that encompasses many aspects of our daily lives. It includes material well-being, relationships with family and friends, and emotional and physical health. It includes work and entertainment, how one feels about one's community and personal safety.

Individual to societal security by building on to human development. Freedom within a broader set of conceptions about wellbeing and security. People give more consideration to the security of their living surroundings. They tend to remain in places where there is security. These places later turn into settlements; civilization will arise with a culture.

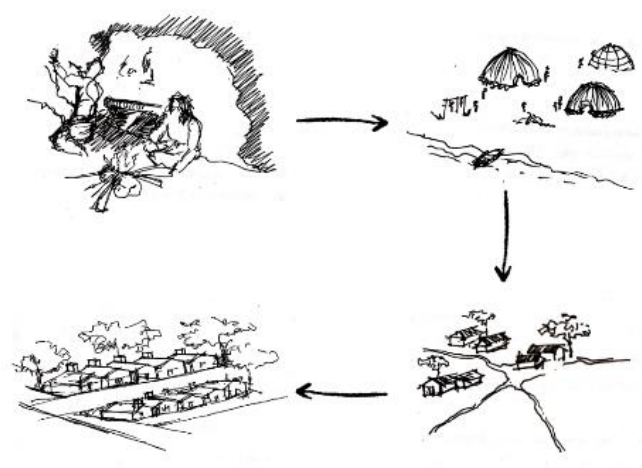

Figure 1: Evaluation of housing concept (Drawn by Author) 
In this process, people choose the places near the rock caves and later they tend to build their settlements using timber and other usable parts of the trees. In Sri Lanka, we got different types of settlements with a variety of houses known as vernacular architecture, which was unique to every place. This system has been in evolution and now we see it has come up to the concept of housing complexes. (See figure 01)

Main types of the housing complexes/schemes in Sri Lanka

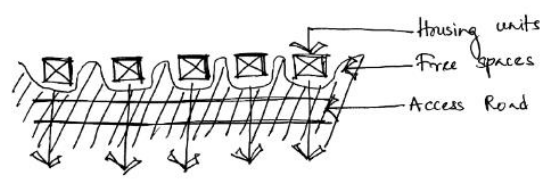

Single sided housing area

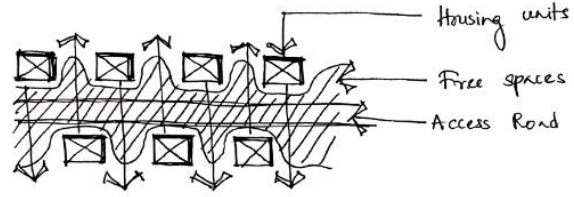

Double sided zigzag shape housing complexes
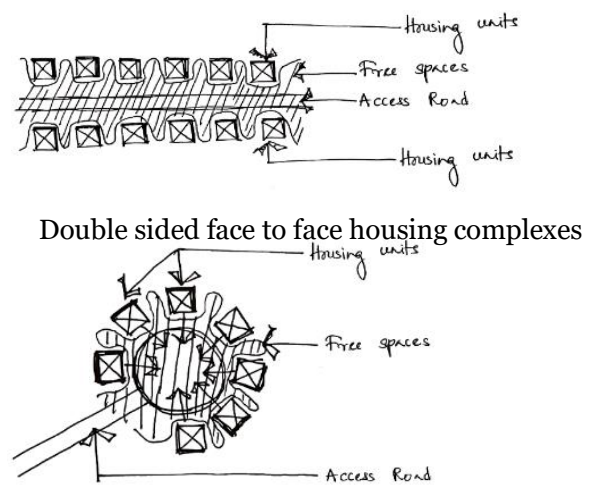

Round shaped housing complexes

Figure 2:Styles of Housing complexes in Sri Lanka (Drawn by Author)

At the present, the housing complexes are built by considering the living quality, and the social levels.

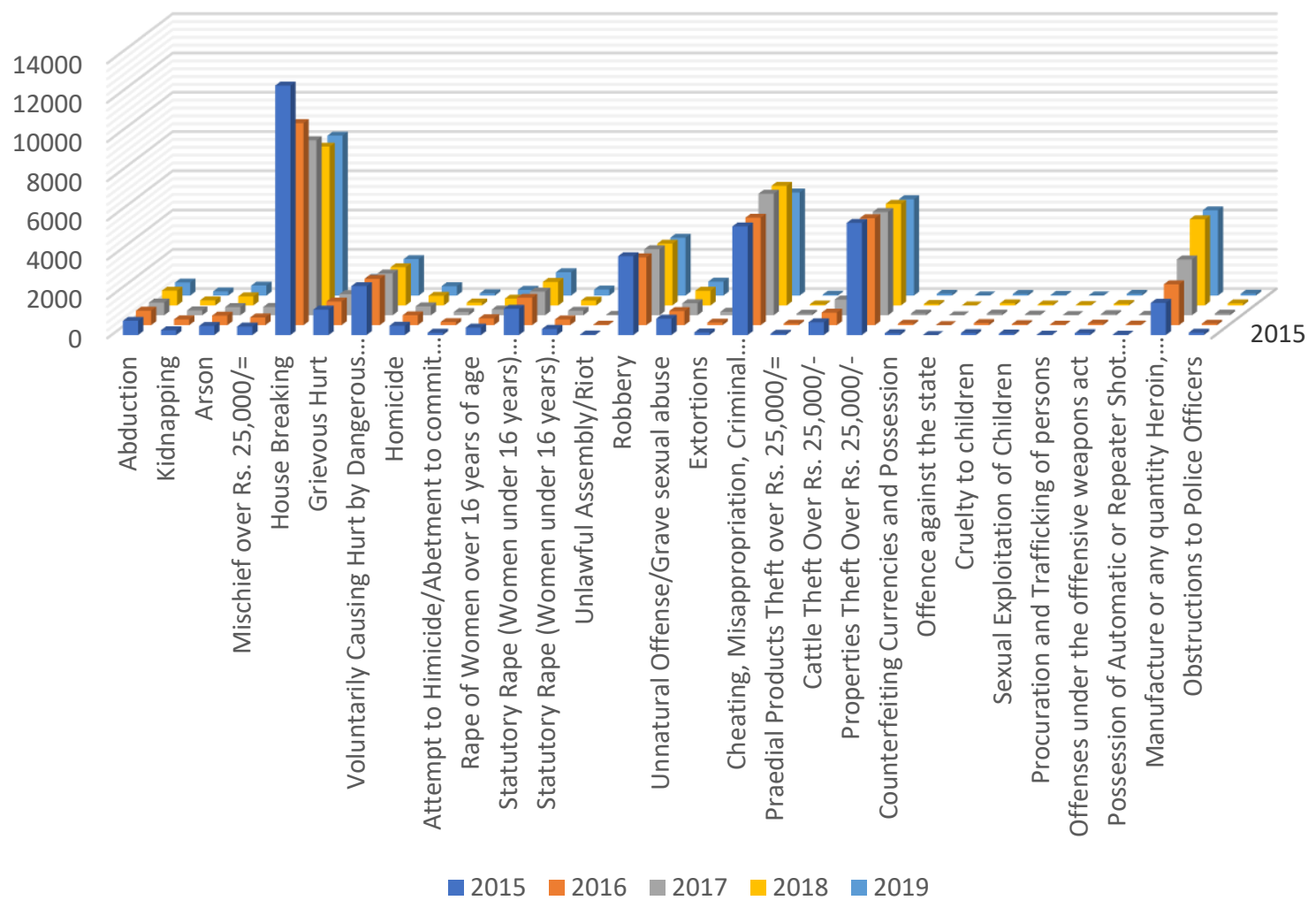

Figure 3: Grave crime abstracts for the year 2015 to 2019 in Sri Lanka (Source: Compiled by author)

When we consider the grave crime abstract for the last four years in Sri Lanka, housebreaking takes the first place. As an undergraduate landscape architecture student, this research is to illustrate an approach to study the impacts of landscape architecture on outdoor insecurity in urban housing complexes. 


\section{Literature Review}

\subsection{INTRODUCTION}

This section will describe the theories, design solutions, and discussion about other researches on crime prevention and the perception of security improvements of exterior features in the urban housing complex landscapes. The topic of crime prevention is broad and covers many different environmental conditions. Landscape architects have been concerned with the crime committed in urban centers and residential communities; as well as, the effect it has had on the human psychology. Urban housing complexes are within these urban neighborhoods and have similar security concerns in the landscape architecture.

Millennium city urban housing complex in Athurugiriya is one such urban neighborhood that has been done as first and foremost development for middle-income families. These families experienced fear in crime and crime-related scenes in the starting periods of the complex. Landscape Architects and other Designers gave solutions to consider the issues related to crime events. My research will focus on the outcomes of these crime-related landscape solutions whether these solutions are successful.

\subsection{WHAT IS CRIME?}

Oxford English Dictionary a crime is an unlawful act punishable by a state or other authority. The nature of crime can be defined as a product of civilization. Any human behavior can have the potential to the crime according to the perception of civilization. It is by a consensus or by a rule created by the dominant power that a specific act becomes a crime. According to crime, created its corresponding punishment. The more unbearable crime gets the more severe the punishment, the greater the fear of being caught committing that unlawful act.

From the social programs in neighborhoods to specific design guidelines for new developments are alternative methods, In recent years, the government and other institutions in charge of crime control. Many studies by theorists such as Scar Newman, Claire Cooper-Marcus and Jane Jacobs have greatly is to consider an approach with multi solutions to the problem (create the physical landscape and social landscape for control and prevention the crime).

\subsection{PHYSICAL LANDSCAPE}

Urban designers Jane Jacobs, The Death and Life of Greate American Cities (1961), and Oscar Newman, who defined defensive spaces (1972), began to examine the conditions in successful urban areas and introduce new theories that compare them with inconvenient locations. In an investigation to understand the physical environment for crime prevention and to find the connectivity between a planned city according to Jacob's perspective. From her observations, Jacobs determines three main qualities of what a street of successful city neighborhood needs,

1. Finding no.1 - a clear boundary between public space and private space, where we could observe this mismatch between private and public spaces.

2. Finding no.2 - The eyes of the natural owners towards the streets, from households, buildings is a must. The buildings which are equipped to handle visitors should be oriented to the street. They cannot turn back or head sideways and leave it blind.

3. Finding no.3 - sidewalk users need to be more consistent, adding to the number of street eyes and encouraging a sufficient number of people in buildings along the street to view the sidewalks. No one likes to look out a window on an empty street. Almost no one does such a thing. Lots of people enjoy watching street activities, outdoors and having fun. (Jacobs 1961, p. 35).

I am sure that we can adopt these findings from her to Sri Lankan cities, to be developed as crimeless effective surroundings.

\subsection{SOCIAL LANDSCAPE}

Ray Jeffery focused on criminal psyche and behavior, rather than the built environment. Jeffery states: "If we are to build a man-environment model or an environment-organism-environment model, we must have a psychological model of behavior". Examining criminal behavior studies, he concluded that there is a separation between offense areas and offender areas (where criminals live). Timothy Crowe Provides 
instruction and training on law enforcement and provides crime prevention guidelines for landscape architecture, urban planning, space management, and architectural planning. Crow believes that the concept of crime prevention through environmental design (CPTED) is to manipulate the physical environment, thereby reducing the fear of crime and activity.

"Surveillance strategies are typically classified as organized (e.g., police patrol), mechanical (e.g., lighting), and natural (e.g., windows)" (Crowe 1991, p. 30).

\subsection{PROSPECT, REFUGE, AND ESCAPE}

Whilst we are no longer hunters and gatherers, the landscapes we find aesthetically satisfying are rooted in the environment's capability to answer a biological drive." (Sugihto, 2016).

In addition to Appleton's (1975) theory of prospect and refuge, Fisher and Nasser include the opportunity for escaping to the equation. The perception of secure, people need to feel that they can escape if threatened and find others to help them with their needs.

\subsection{METHODOLOGY AND CONCEPTUAL FRAMEWORK}

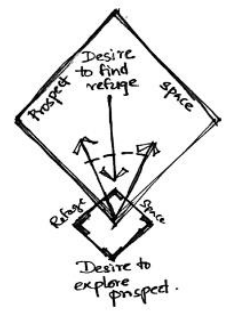

Figure 4: prospect and refuge

(Drawn by Author)

A survey was conducted to identify perceived secure and insecure exterior sites on the Millennium city housing complex. The findings are compared to a crime map to see if these sentiments are true to the threat of actual crimes. Next, four designs determinants were applied to the results of the survey in two selected "secure" and two selected "insecure" areas.

The study was conducted to incorporate findings on how people better understand their surroundings and perceptions of security to improve the planning and design decisions for the Millennium City Housing Complex.

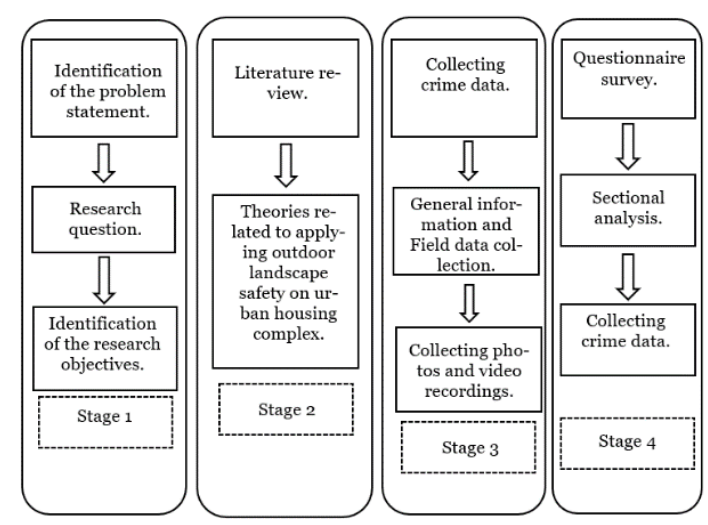

Figure 5: Conceptual framework for the research (Source: Compiled by author)

\section{Data Presentation of the Case Study Analysis}

\subsection{LOCATION AND ACCESSIBILITY}

Athuruguiriya expressway entrance is $2.9 \mathrm{Km}$ away from the E02 expressway. MCHC has situated $1.4 \mathrm{Km}$ away from Athurugiriya city. The closest town next to MCHC is Kaduwela which is a $7.5 \mathrm{Km}$ distance.

95 acres of this is divided into 7 parts. Yellow dots are as entrances for the residential areas. Here there is only one entrance and one exit for each residential area. 


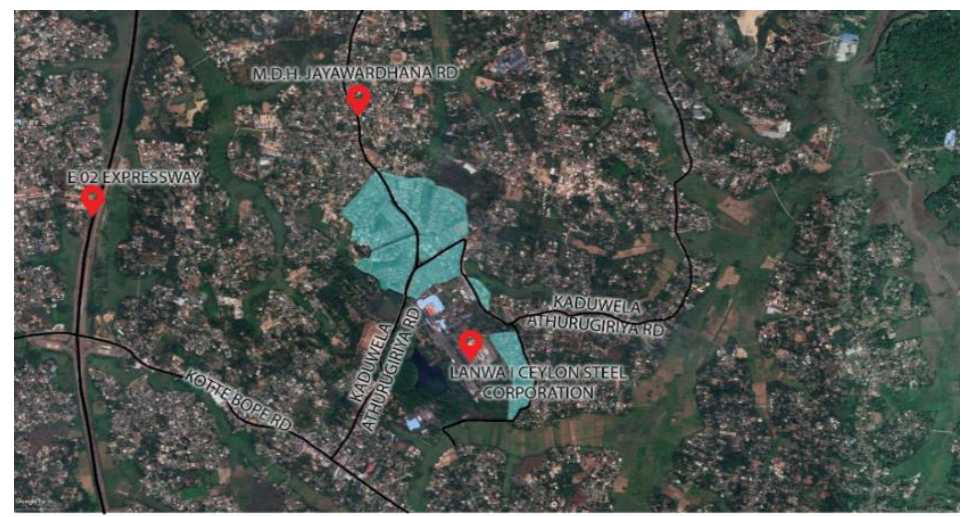

- MILLNIUM CITY HUSING SCHEME

Figure 6: road network in millennium city housing complex context

(Source: google image compiled by Author)
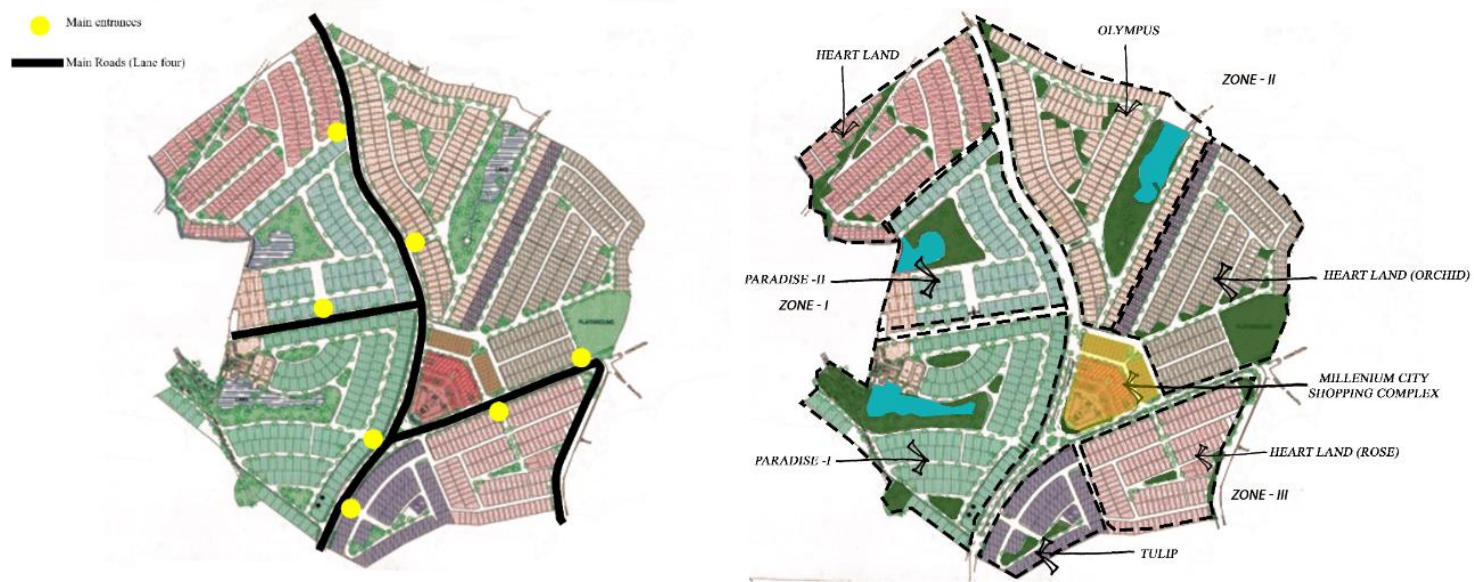

Figure 7: road network within site area

(Drawn by Author)

\subsection{EVOLUTION OF MILLENNIUM CITY HOUSING COMPLEX}

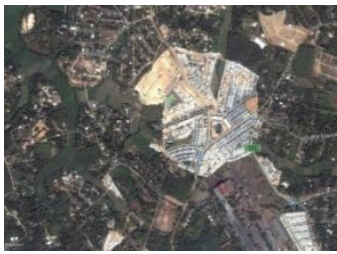

2004

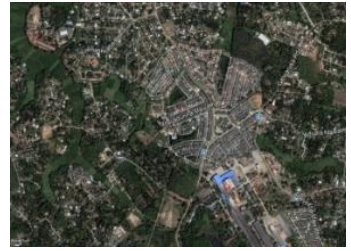

2008
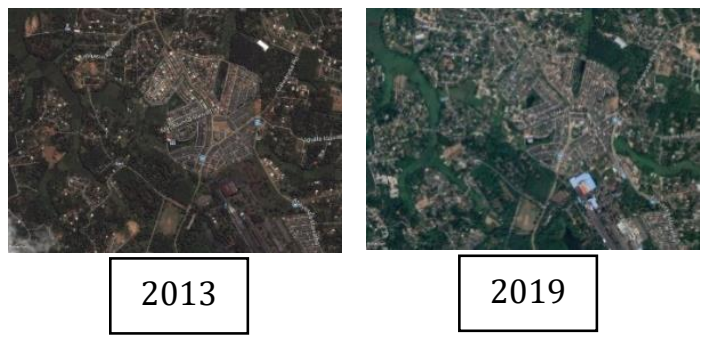

2019

Figure 8: satellite view in MCHC

(Source: google image compiled by Author)

In 2004, most of the development was finished in paradise 01 and paradise 02 , and the people were settled into the area. Here we could observe an alien landscape when considering the whole context.

In 2008 the plantation work and building work was finished, but yet there were some houses still in construction. The Millennium city housing complex could be observed that is partially getting adopted to the context (See figure 8). In 2013 we could observe still the alien look could be observed while in 2020 image shows the housing complex fully adapting to the city context. Built environment footprint rapidly increased due to urbanization (ecological footprint decreases). The green coverage landscape rapidly decreases. This is an effect on the outdoor security in the landscape. 


\subsection{POLICE INFORMATION AND CRIME MAPS}

$\begin{array}{lccc} & 2000-2010 & 2011-2015 & 2016-2020 \\ \text { Murder/Non-Negligent Homicide } & 1 & 1 & 0 \\ \text { Forcible Rape/Sexual Assault } & 2 & 1 & 0 \\ & & & 1 \\ \text { Armed Robbery } & 5 & 75 & 20 \\ \text { Burglary of residence } & 170 & 12 & 4 \\ \text { Drug dealing incidents } & 35 & 5 & 3 \\ \text { Motor vehicle theft } & 12 & 1 & 2 \\ \text { Illegal weapons imposition } & 2 & 97 & 30 \\ & & & \end{array}$

Table 1: crime incidents in MCHC selected area

(Source: Athurugiriya police department)

These are the crime incidents according to the police reports. We can divide this to periods where the crimes that happened, in 2000-2010,2011-2015, and 2016. -2020. According to the above data analysis, the crimes that happened between 2000 to 2010 gradually decreases, but still the housebreakings are showing the same amounts without any decrease.

\subsection{SURVEY RESULTS}

This survey was used to analyze the residents' perception of MCHC security. From the resident population, 48 subjects were randomly selected, of which 28 were male and 20 were male. There were only 46 residents in the Millennium City housing complex, and the remaining two residents were out of the MCHC.

A large number of residents, 40 of the 48 surveyed, commute to the millennium city housing complex by vehicle. The rest was divided between using the public transportation system and walking to the Millennium City Housing Complex. Subjects surveyed were asked to circle two areas of the housing complex that they thought was "insecure" and "secure." The results were dramatically illustrated in the unsafe and unprotected areas of the housing complex.

The perceived "insecure" locations (see Figure 9,11) were scattered across the Millennium city housing complex while the perceived "secure" locations (see Figure 10,12) were concentrated in two areas.

The areas perceived "insecure" on housing complex chosen by male and female residents were:

1. millennium city Olympus residents

2. millennium city tulip residents

3. millennium city heartland

4. millennium city rose residents

The areas perceived "secure" on millennium city housing complex were:

1. millennium city paradise 01

2. millennium city paradise 02

3. millennium city orchid residents

The two areas perceived by the subjects to be "insecure" were the Olympus and tulip.

Olympus residents located in the upper side of the millennium city housing complex, largest housing complex zone in millennium city housing complex, 252 housing units were there. Most of the people are upper-middle incomers. Residents overwhelmingly mentioned these areas as insecure for isolating this section and less connectivity with other residences and also a lot of people in upper-middle-income rage, they busy with work, so less connectivity with the neighborhood. 


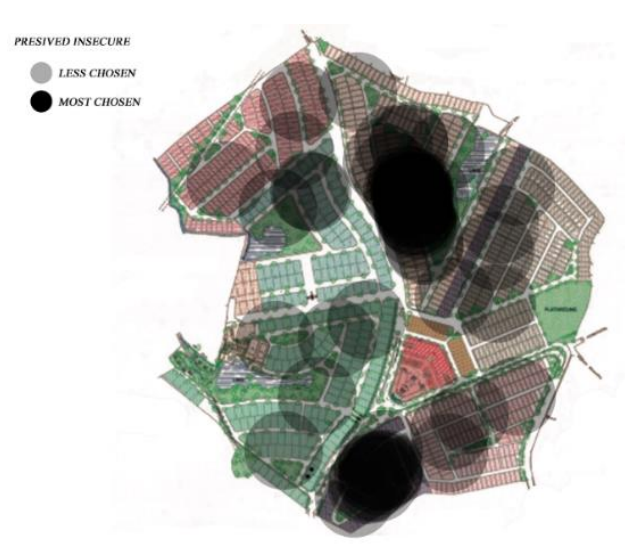

Figure 9: Perceived "insecure" areas circled by subjects on the millennium city housing complex. (Source: Google image)

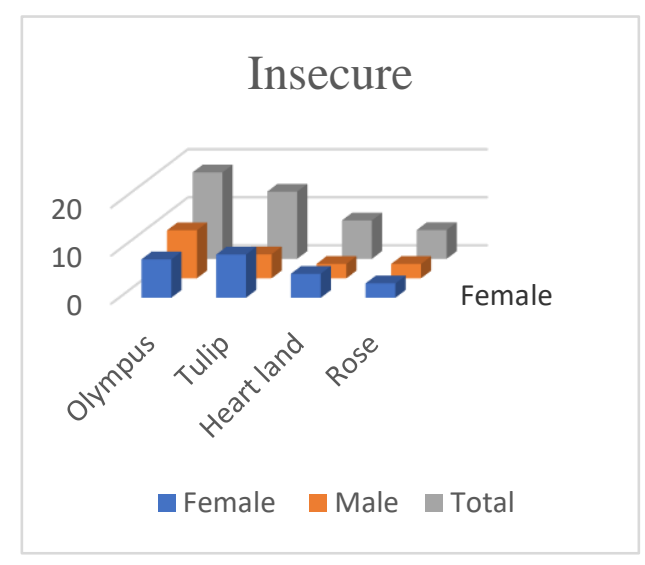

Figure 11: Perceived "Insecure"

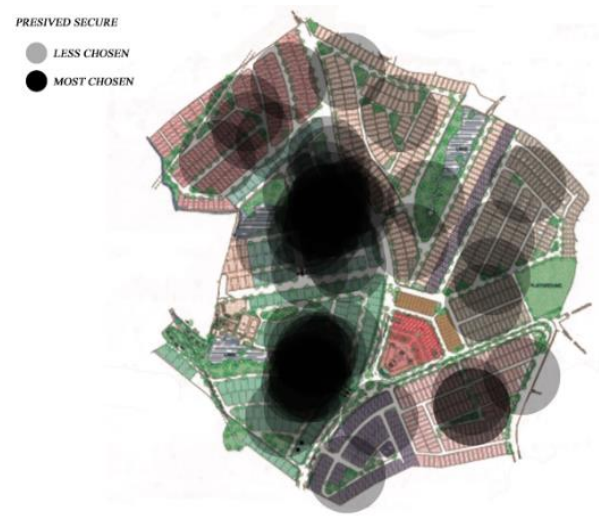

Figure 10: Perceived "secure" areas circled by subjects on the millennium city housing complex. (Source: Google image)

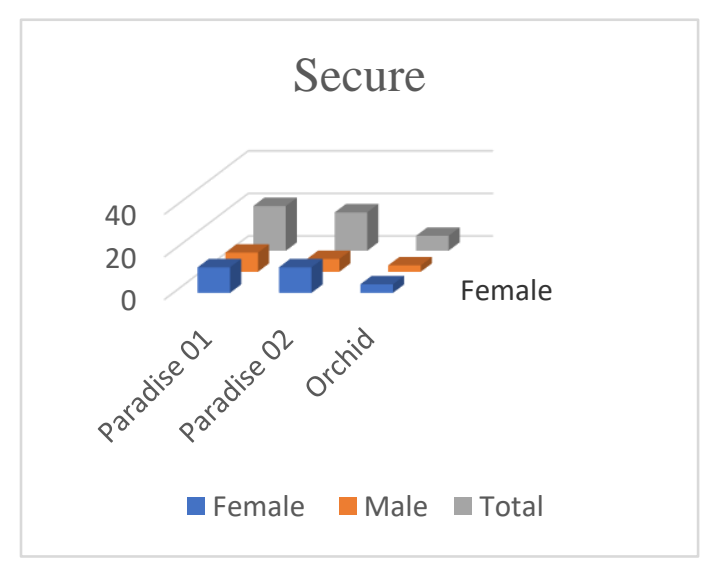

Figure 12: Perceived "Secure"

Another location resident perceived as "insecure," was the tulip residence area. It's at the beginning of the millennium city residential area. 72 one-story housing units were there and this is the smallest housing complex in the millennium city housing complex. One side is covered with Oruwala steel cooperation and the other side is covered with the marshy area.

In contrast to the perceived "insecure" outdoor areas on MCHC, the perceived "secure" locations were concentrated in two areas, paradise -01 and paradise -02 .

These residential areas are the first two completed residential areas in the millennium city housing complex. In these two places, people interactions are high. They have an annual event for improving the interactions with their neighborhoods. And very generous peoples were there.

\subsection{CRIME MAP COMPARISON RESULTS}

The crime map is a compilation of crimes reported on the millennium city housing complex. The crimes were divided into main 3 time zones. 2000 - 2010, 2011 - 2015, and 2016 to 2020. The crime data was collected from the Athurugiriya police station.

Symbols were created for the crime types and noted on the crime map. The purpose is to analyze and compare the survey results of the two perceived "insecure" and the two perceived "secure" areas of the housing complex with the actual crimes committed to the time zones. 


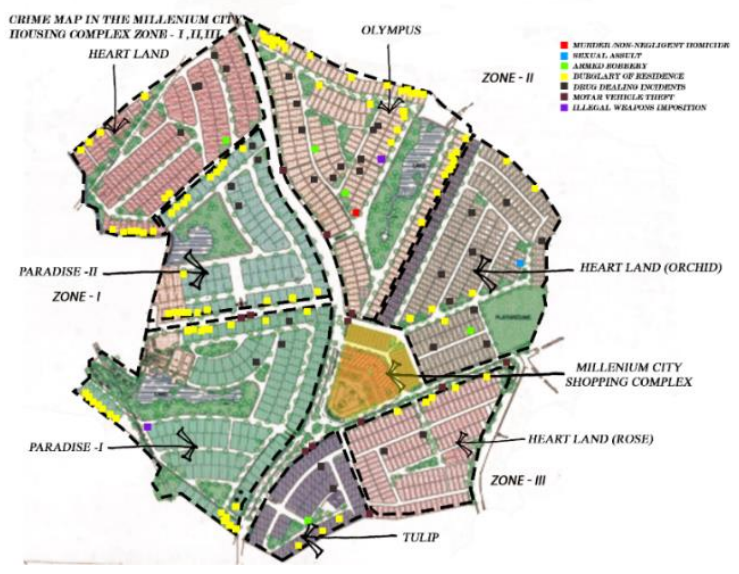

Figure 13: This is the $2000-2010$ crime incidents in one map. (Source: Drawn by Author According to the police crime records)

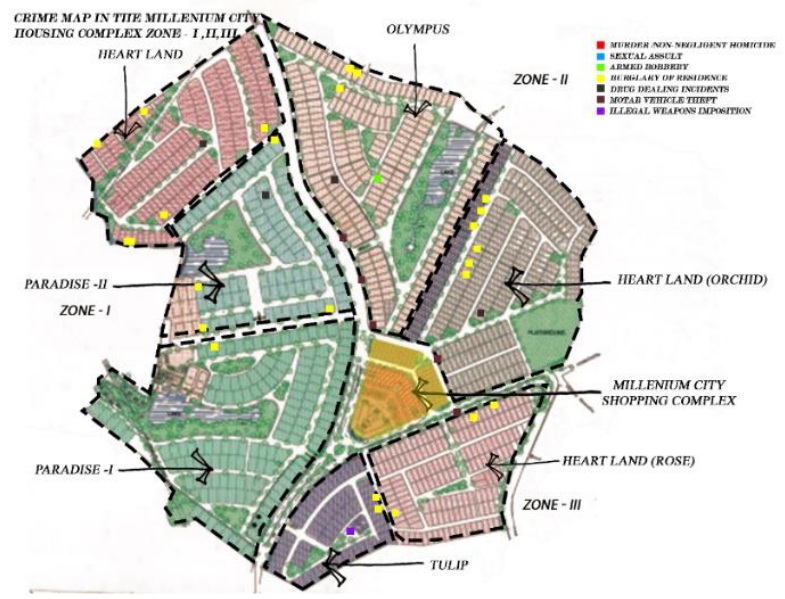

Figure 14: This is the 2011 - 2016 crime incidents in one map. (Source: Drawn by Author According to the police crime records)

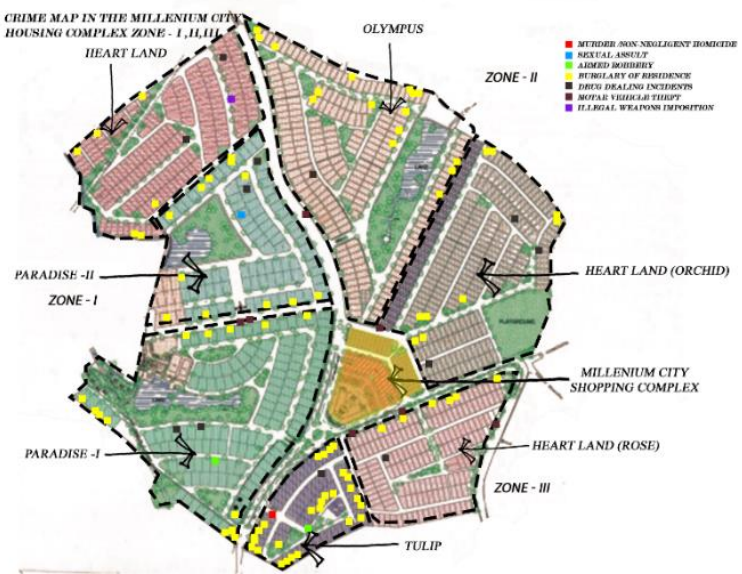

Figure 15: This is the 2016 - 2020 crime incidents in one map. (Source: Drawn by Author According to the police crime records) 
According to these three crime maps, in 2000 - 2010 one murder case happened in the Olympus area. Police records were given to information. Pillayans' Secretary has been shot and killed in the Olympus residential area and according to the police records, 2011 - 2015 one murder case at the tulip residential area. The body of a person, who is believed to have been shot and killed, has been found inside a residence at Millennium City tulip in Athurugiriya. At the beginning of the millennium city, housing complex lot of cases are reported on the burglary of a residence.

Millennium city in the 2000 era is alien to that context so a lot of burglaries around residences werehappening. At the beginning of the millennium city, communication with neighborhood residentials was in a lower condition. Most of the house owners used to leave the house in the morning, while the houses were left alone in the evenings. This was a reason for most crime incidents.

\subsection{CRITERIA FOR SAFE SPACE}

\subsubsection{High prospect, low refuge, and escape}

\subsubsection{High prospect}

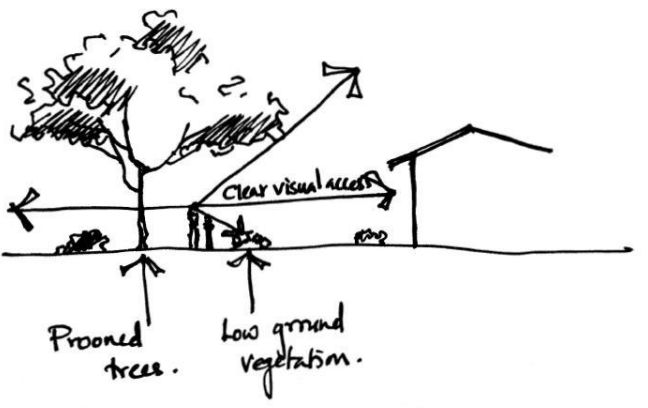

Figure 16: high prospect (Drawn by Author)
The clear visual access towards the visual field is bringing high prospect to the user. This clears the user's mindset, by making sure of the environment's safety, which he/she is dealing with. The perception of security is a connective factor with "high prospect".

High prospect is the high opportunity to acquire visual information, to explore the environment. The prospect can be clearly identified with low disturbance to the visuals. (Figure 16)

The more beautiful vistas and visual information that is present in the environment, the more beautiful vistas and visual information that is present in the environment, the more it will be a high prospect neighborhood landscape. Management activities are a must in maintaining the prospect to a user-friendly environment, where pruning, cutting, and cleaning must be done in a user-friendly method.

\subsubsection{Low refuge}

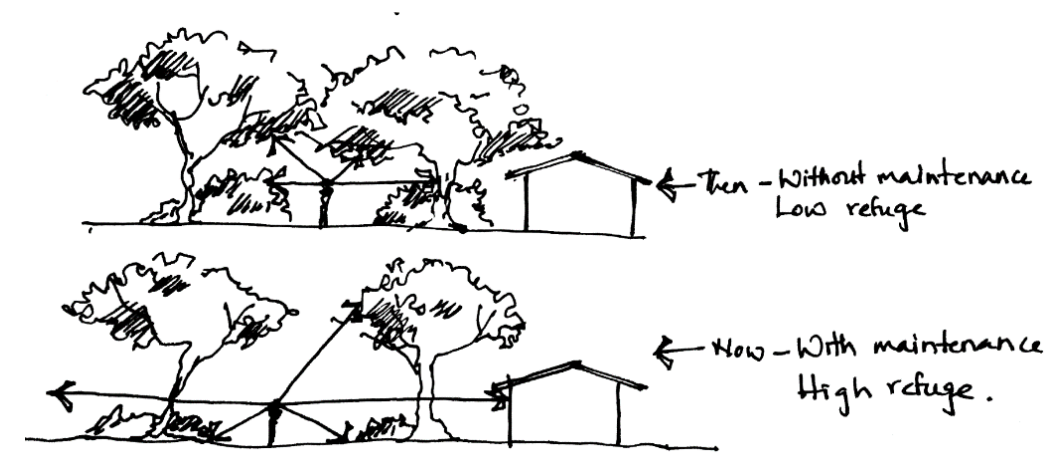

Figure 17: maintenance effectiveness in creating high refuge spaces (Drawn by Author)

The low refuge is the lowering of environments that can hideaway. Refuge comes in predator examples in primal man's evolution history where predators used to choose shaded places under a tree where the prey could not see the predator in the light, with a huge contrast between light and shade. Even though the predator sees they can stay without being seen. To improve neighborhood security lowering the number of refuge places will decrease the capability of a stranger to be comfortable in the surrounding. (Figure 17) 3.6.1.3. Escape 


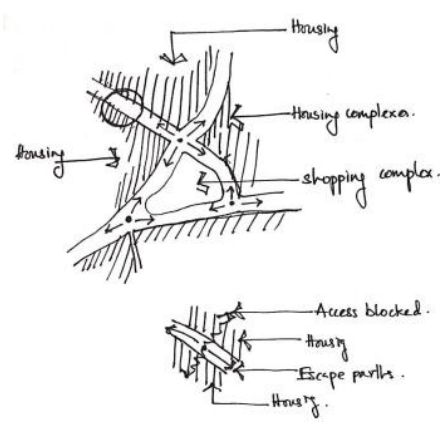

Figure 18: low escape places (Drawn by Author)

\section{Conclusion}

The research aim is to investigate the impacts of landscape architecture to reduce outdoor insecurity in urban housing complexes and to identify the landscape characters to improve the security in urban housing complexes using landscape architecture. CPTED theory, prospect, refuge, and Escape was identified as a Landscape Architectural approach to the study. MCHC consists of 06 zones. Three zones out of them were selected for further studies with seven residential areas within these three selected zones. The structured interview was done to a randomly selected group with 48 subjects answering the questions and giving general information about MCHC. Then the crime maps were made with the information that was collected from Athurugiriya Police station which was made into 3 time zones as 2000-2010, 2011- 2015, 2016 - 2020.

The last analyzing segment was a sectional analysis of the MCHC site area. According to the police reports, the crime rate in the area gets decreased after renovation; because of the planning activities and the changes that have been done after the 2002 incident inside MCHC (See table 02). In the study, identification of how the CPTED theory, "high prospect", "Low refuge', and 'escape' aspects had been applied into the housing complex was done.

When considering the sectional analyses of this dissertation, comparing with the crime maps and analyzing perceived secure insecure places, "Yes" there is an impact of the landscape to reduce the outdoor insecurity and reduction of crime.

The research clearly illustrates that the interconnection between the neighborhood is very low with its housing arrangement as "Double-sided" (See figure 02). Here the lack of natural surveillance provides positive spaces for criminal activities in the outdoor landscape which is a character that was identified as a reason for the crimes inside the housing complex.

Reducing the construction of concrete walls which cover the front yards, implementing wire meshed fences, and increasing the road width inside the housing complex were identified for the improvement of Natural Surveillance. The findings of this research can be continued with further studies on the Urban housing complexes and also for the architectural structures of houses that can be designed combined with the outdoor landscape insecurity.

This research contributes to identifying the landscape character to reduce crime, in relation to the Urban housing complexes where there is a lack of knowledge in applying theories to the sustainable landscape architectural work in planning and designing. The research findings will challenge the planning and designing fields on building up secured outdoor landscape places for housing complex neighborhoods.

\section{References}

Appleton, J. (1975) The experience of landscape, rev edn. Wiley, London

Crowe, T. D. (1991). Crime Prevention Through Environmental Design: Applications of Architectural Design and Space Management Concepts. Stoneham: ButterworthHeinemann.

Edward J. Blakely and Mary Gail Snyder, J. C. (1997). Architecture of Fear. (N. Ellin, Ed.) New York: Princeton Architectural Press.

Fernandez, M. F. (2005). Crime prevention and the perception of safety in campus design. Retrieved from LSU Master's Theses: https://digitalcommons.lsu.edu/gradschool_theses/1483

Jacobe, J. (1961). The Death and Life of Great American Cities. New York: Random House.

Michael, S. E. ( 2002). CPTED and Vegetation: A Primer on Planting Design for Law. Landscape Architecture 92, 24-29. 
Mr Lim Tow Fok, M. J. (2003). Crime Prevention Through Environmental Design Guidebook. Singapore 329560: National Crime Prevention Council.

New Oxford English Dictionary Second Edition on CD-ROM. (2009). Oxford: Oxford University Press.

Newman, 0. ( 1972). Defensible Space: Crime Prevention Through Urban Design. New York: Collier Books.

Skogan, W. D. ( The Free Press). Crime and the Spiral of Decay in American. New York: 1990.

Sugihto, E. (2016, may 17). Prospect - refuge theory. Retrieved from https://medium.com: https://medium.com/@social_archi/prospect-refuge-theory-ca5d80379e51 